\title{
ANALISIS MANAJEMEN PENCEGAHAN DAN PENANGGULANGAN KEBA- KARAN DI PUSKESMAS KECAMATAN CIPAYUNG JAKARTA TIMUR
}

\author{
Analysis Of Management Prevention And Fight Fire At The Health Center of \\ Cipayung East Jakarta \\ Nazarwin Saputra ${ }^{1}$, Winda Cinkarila Saputri ${ }^{2}$ \\ ${ }^{1}$ Program Studi Kesehatan Masyarakat Universitas Muhammadiyah Jakarta \\ ${ }_{2}^{2}$ Pusat Kesehatan Masyarakat Kecamatan Cipayung \\ E-mail: nazarwinepid@gmail.com
}

\begin{abstract}
ABSTRAK
Kebakaran merupakan suatu peristiwa atau kejadian yang sangat merugikan semua pihak. Dalam menjamin dan menjaga keselamatan hidup pasien, pegawai dan pengunjung. Upaya pencegahan dan penanggulangan tersebut bertujuan untuk mengantisipasi secara dini terhadap bahaya kebakaran sehingga tercipta lingkungan kerja yang selamat, bersih, nyaman, dan bebas dari sumber sumber bahaya kebakaran. Data diperoleh secara langsung dengan cara observasi langsung dan wawancara dengan pihak terkait serta studi pustaka. Hasil penelitian ini adalah upaya-upaya yang telah dilakukan untuk pencegahan dan penanggulangan terhadap bahaya kebakaran di Puskesmas Kecamatan Cipayung diketahui bahwa Puskesmas Kecamatan Cipayung telah menyediakan sarana untuk pemadam kebakaran seperti APAR, tim pemadam dan usaha- usaha lain seperti pemasangan fire alarm system, tanda peringatan dan tersedianya assembly point. Penelitian ini menyimpulkan bahwa Puskesmas Kecamatan Cipayung telah melaksanakan upaya pencegahan dan penanggulangan kebakaran antara lain dengan penyediaan sarana pemadam kebakaran seperti APAR, tim pemadam dan usaha-usaha lain seperti pemasangan fire alarm system, tanda peringatan dan tersedianya assembly point. Saran yang dapat diberikan adalah untuk penambahan pemasangan dan penempatan poster atau papan peringatan, penambahan sarana pemadam kebakaran seperti water sprinkle dan hydrant, peningkatan wawasan dan ketegasan terhadap peraturan-peraturan yang ada dan peningkatan pelatihan mengenai pencegahan dan penanggulangan kebakaran kepada karyawan.
\end{abstract}

Kata Kunci : Pencegahan, Penanggulangan, Kebakaran

\begin{abstract}
Fire is an event or event that is very harmful to all parties. In ensuring and safeguarding the lives of patients, employees and visitors. Prevention and mitigation efforts are intended to anticipate early on the fire hazard so as to create a safe, clean, comfortable, and free work environment from sources of fire hazard. The data were obtained directly by direct observation and interview with related parties and literature study. The results of this research are the efforts that have been done to prevent and overcome the fire hazard in Puskesmas Kecamatan Cipayung known that Puskesmas Kecamatan Cipayung have provided fire extinguishers such as APAR, firefighting team and other efforts such as installation of fire alarm system, and the availability of assembly points. This study concluded that Puskesmas Kecamatan Cipayung has implemented fire prevention and prevention efforts, among others, by providing fire extinguishers such as APAR, fire extinguishers and other efforts such as installation of fire alarm system, warning sign and availability of assembly point. Suggestions that can be given are for the addition of installation and placement of posters or warning boards, the addition of fire extinguishers such as water sprinkle and hydrant, increasing insight and firmness to existing regulations and improvement of fire prevention and fire management training to employees.
\end{abstract}

Keywords : Prevention, Countermeasures, Fire

\begin{tabular}{lll}
\hline Sekretariat & \multicolumn{2}{l}{ Article History: } \\
Editorial: Kampus FKM UNISMUH PALU - Palu 94118, & $\Rightarrow \quad$ Received 26 Januari 2018 \\
$\quad$ Sulawesi Tengah, Indonesia & $\Rightarrow$ & Revised 2 Februari 2018 \\
Telp/HP: +6281245936241, Fax (0451) 425627 & $\Rightarrow$ & Accepted 25 April 2018 \\
E-mail: jurnal.mppki@gmail.com & $\Rightarrow$ & Available online 25 Juni 2018 \\
OJS: $\underline{\text { http://iurnal.unismuhpalu.ac.id/index.php/PJKM }}$ &
\end{tabular}




\section{PENDAHULUAN}

Pusat kesehatan masyarakat merupakan layanan publik yang berorientasi lebih kepada pada bidang preventif berbasis masyarakat. Dalam memberikan pelayanan kepada pasien sepatutnya ada standar operasional prosedur (SOP) untuk melindungi pasien dan paramedik. Lingkungan kerja puskesmas dan jenis pekerjaan yang bervariasi serta segala fasilitas dan peralatannya, harus dipelihara sedemikian rupa untuk menjaga keselamatan dan keamanan serta mencegah kebakaran dan persiapan menghadapi bahaya. Puskesmas merupakan garda terdepan dapalm pencegahan jika terjadi kegawat daruratan maupun memberikan keterampilan pertolongan sesuai dengan kemampuan (Ditjen Binkesmas Depkes, 2005).

Menurut Undang-Undang No 1 Tahun 1970 Bab II Pasal 2 tentang ruang lingkup keselamatan kerja, bahwa aspek keselamatan kerja harus diimplementasikan dalam segala tempat kerja, baik di darat, di dalam tanah, di permukaan air, di dalam air maupun di udara, yang berada di dalam wilayah kekuasaan hukum Republik Indonesia. Salah satu aspek keselamatan kerja tersebut adalah keselamatan dari bahaya kebakaran maupun ledakan. Kebakaran merupakan suatu peristiwa atau kejadian yang sangat merugikan semua pihak, baik pihak pengelola atau pengguna gedung, pemilik gedung, maupun masyarakat yang berada di sekitar gedung. Kebakaran merupakan salah satu kecelakaan yang kerap terjadi. Kebakaran dapat merusak lingkungan serta gangguan kesehatan akibat dari asal kebakaran serta kerugian material. Penerapan keselamatan dan kesehatan kerja sebagai upaya pencegahan dan penanggulangan kecelakaan termasuk kebakaran Upaya tersebut meliputi pencegahan, penanggulangan, pengamatan dan pemadaman kebakaran dan meliputi perlindungan jiwa dan keselamatan manusia serta perlindungan harta kekayaan. Upaya penanggulangan dan pecegahan kebakaran salah satunya adalah dengan menyediakan instalasi APAR dan hydrant (Suma'mur, 1989, Gempur Santoso, 2004).

Puskesmas Kecamatan Cipayung, Jakarta timur berupaya menjamin dan menjaga keselamatan hidup pasien, pegawai dan pengunjung, Puskesmas Kecamatan Cipayung perlu memiliki sistem manajemen penanggulangan kebakaran dan bencana alam. Oleh karena itu, usaha pencegahan dan menanggulangi kebakaran dan bencana alam di lingkungan Puskesmas Kecamatan Cipayung dalam pelaksanaannya perlu adanya partisipasi dan peran serta dari seluruh karyawan dalam usaha keselamatan pasien maupun karyawan yang merupakan bagian tidak terpisahkan dari semua kegiatan puskesmas dalam rangka menunjang peningkatan produktivitas secara aman dan efisien. Maka dari latar belakang diatas peneliti ingin menganalisis manajemen pencegahan dan penanggulangan kebakaran di Puskesmas Kecamatan Cipayung Jakarta Timur.

\section{METODE PENELITIAN}

Penelitian ini adalah kualitatif study dan literatur review. Penelitian ini dilaksanakan di wilayah puskesmas Kecamatan Cipayung Jakarta Timur. Data pada penelitian ini diambil dengan berbagai macam cara diantaranya : studi pustaka, yaitu mencari referensi dan literatur yang terkait dengan kegiatan yang menjadi data pelengkap dan pembanding dengan data yang ada. Data yang didapatkan kemudian dibandingkan dengan Peraturan atau Undang-Undang yang berlaku. Wawancara terstruktur dengan metode indept interview, yaitu metode pengambilan data primer secara lisan. Wawancara dilakukan untuk mendapatkan penjelasan dan klarifikasi atas permasalahan-permasalahan teknis yang dianggap perlu yang terjadi di lapangan dengan menanyakan langsung kepada pihak yang terkait (informan). Pengamatan lapangan, yaitu pengamatan secara langsung disertai dengan praktik pada instansi yang sedang berlangsung. Informan pada penelitian ini adalah petugas puskesmas Kecamatan Cipayung. Validasi data dilakukan dengan triangulasi. Bahan yang digunakan adalah survey kit penelitian kualitatif.

\section{HASIL}

\section{Sarana Pemadam Kebakaran Aktif Alat Pemadam Api Ringan (APAR)}

APAR yang tersedia di Puskesmas Kecamatan Cipayung adalah berjenis dry chemical (powder). Jumlah APAR yang tersedia berdasarkan data pemeriksaan yang ada adalah Lantai 1 memiliki 4 unit APAR, 2 unit 
APAB, Lantai 2 memiliki 3 unit APAR, Lantai 3 memiliki 3 unit APAR dan Lantai 4 memiliki 2 unit APAR, 1 unit APAB. Jadi jumlah APAR yang tersedia di Puskesmas Kecamatan Cipayung adalah sebanyak 15 unit.

\section{Sarana Pemadam Kebakaran Pasif Fire Alarm System}

Fire alarm system di Puskesmas Kecamatan Cipayung berjumlah 4 unit, dimana pada tiap-tiap lantai terdapat 1 unit fire alarm. Fire alarm system di Puskesmas Kecamatan Cipayung menggunakan sistem otomatis dalam pengoperasiannya. Sistem otomatis yang dimaksudkan adalah apabila terjadi kebakaran maka alat pendeteksinya yang bekerja secara otomatis dengan system deteksi panas.

\section{Emergency Respons Plan}

Untuk menghadapi keadaan darurat yang terjadi di Puskesmas Kecamatan Cipayung, maka Puskesmas Kecamatan Cipayung telah membentuk tim untuk menangani keadaan darurat. Untuk meningkatkan pengetahuan dan keterampilan tim maka Puskesmas Kecamatan Cipayung memberikan pelatihan dan simulasi untuk menghadapi keadaan darurat.

\section{Assembly Point}

Di Puskesmas Kecamatan Cipayung telah menyediakan tempat berkumpul sementara atau assembly point yang letaknya sudah diperuntukkan untuk tempat yang aman bagi karyawan yang tidak terlibat langsung dalam penanggulangan keadaan darurat dengan pemasangan tanda yang jelas bertuliskan assembly point.

\section{Tanda Peringatan}

Di Puskesmas Kecamatan Cipayung telah memasang tanda peringatan mengenai keselamatan kerja yang diletakkan di seluruh area tempat kerja terutama di tempat-tempat yang mudah terlihat oleh pekerja. Tanda peringatan ini dibuat dan dipasang sebagai pemberitahuan, pengarahan, perhatian dan larangan bagi setiap pekerja dan orang lain yang berada di tempat kerja guna untuk mencegah terjadinya kecelakaan kerja terutama pada saat terjadi bencana atau kebakaran. Tanda peringatan juga dipasang di setiap lift sebagai himbauan agar pekerja dan pengunjung Puskesmas tidak menggunakan lift apabila sedang terjadi bencana atau kebakaran.

\section{Upaya Pencegahan Kebakaran}

Salah satu bentuk upaya pencegahan kebakaran yang dilakukan oleh Puskesmas Kecamatan Cipayung adalah dengan cara mengadakan pelatihan guna meningkatkan pengetahuan karyawan mengenai cara pencegahan dan penanggulangan apabila terjadi kebakaran.

\section{Upaya Penanggulangan Kebakaran Tindakan Penyelamatan}

Untuk tindakan keadaan darurat, Puskesmas Kecamatan Cipayung telah menyediakan jalur atau pintu darurat, apabila ada bahaya kebakaran maka suara sirine akan berbunyi untuk menandakan apabila terjadi kebakaran.

\section{Tim Pemadam Kebakaran}

Tim pemadam kebakaran di Puskesmas Kecamatan Cipayung terdiri dari 3 kelompok yang selalu siap siaga 24 jam dan setiap kelompok beranggotakan 7 orang. Dengan jam kerja secara shift pagi, siang dan malam.

\section{PEMBAHASAN}

\section{Sarana Pemadam Kebakaran Aktif Alat Pemadam Api Ringan (APAR)}

APAR yang tersedia di Puskesmas Kecamatan Cipayung adalah sebanyak 15 unit. Hal ini telah sesuai dengan Kepmenaker No.Kep. 186/MEN/1999 Pasal 2 (b) dan (d) yaitu, "Kewajiban mencegah, mengurangi, dan memadamkan kebakaran di tempat kerja yang meliputi; penyediaan sarana deteksi, alarm sistem, pemadam kebakaran, sarana evakuasi, dan pembentukan unit penanggulangan kebakaran di tempat kerja".

Dari hasil wawancara dengan Tim Penanggung Jawab Keselamatan Kebakaran Gedung (K2G) dan Bencana Alam Puskesmas Kecamatan Cipayung didapatkan informasi , "pada masing-masing APAR telah disediakan form checklist kondisi APAR, apakah masih dalam kondisi baik dan layak pakai atau tidak. Form di isi setiap seminggu sekali dan di isi oleh petugas $\mathrm{K} 3$ 
Puskesmas. Untuk isi ulang APAR dilakukan setiap 6 bulan sekali bekerja sama dengan pihak ketiga. Pemeriksaan APAR terakhir terhitung pada bulan Februari tahun 2017".

\section{Sarana Pemadam Kebakaran Pasif Fire Alarm System}

Fire Alarm System di Puskesmas Kecamatan Cipayung menggunakan sistem otomatis, apabila isyarat tanda bahaya berbunyi maka untuk semua pekerja diwajibkan melakukan tindakan yang aman dan selamat dengan berkumpul di assembly point untuk menunggu tim evakuasi melakukan evakuasi di sekitar tempat kejadian. Semua pekerja diharuskan untuk berkumpul di assembly point guna untuk mempermudah tim evakuasi melakukan evakuasi.

Hal ini telah sesuai dengan Kepmenaker No. Kep. 186/MEN/1999 Pasal 2 (b) yaitu, "Kewajiban mencegah, mengurangi, dan memadamkan kebakaran di tempat kerja yang meliputi; penyediaan sarana deteksi, alarm sistem, pemadam kebakaran, sarana evakuasi, dan pembentukan unit penanggulangan kebakaran di tempat kerja". Dari hasil wawancara dengan Tim Penanggung Jawab Keselamatan Kebakaran Gedung (K2G) dan Bencana Alam Puskesmas Kecamatan Cipayung didapatkan informasi "Gedung Puskesmas ini juga telah dilengkapi dengan Fire Alarm System yang otomatis berbunyi jika terjadi kebakaran dengan system deteksi panas".

\section{Emergency Respons Plan}

Tim yang dibentuk di Puskesmas Kecamatan Cipayung ditugaskan untuk mengatasi keadaan darurat yang terjadi di Puskesmas Kecamatan Cipayung, yang meliputi kebakaran dan gempa bumi. Untuk persiapan dalam menghadapi keadaan darurat tersebut, Puskesmas Kecamatan Cipayung telah menyiapkan beberapa program yaitu pembentukan personil yang bertanggungjawab melaksanakan tugas, fasilitas dan sarana penunjang pelatihan, kerjasama tim, respon awal, serta simulasi.

Hal ini telah sesuai dengan Kepmenaker RI No.Kep- 186/MEN/1999 tentang Unit Penanggulangan Kebakaran di Tempat Kerja (BAB II Pasal 5) yang menyatakan bahwa "Unit penanggulangan kebakaran sebagaimana dimaksud terdiri dari petugas peran kebakaran regu penanggulangan kebakaran, koordinator unit penanggulangan kebakaran dan ahli K3 spesialis penanggulangan kebakaran sebagai penanggung jawab teknis".

Dari hasil wawancara dengan Tim Penanggung Jawab Keselamatan Kebakaran Gedung (K2G) dan Bencana Alam Puskesmas Kecamatan Cipayung didapatkan informasi "Puskesmas Kecamatan Cipayung telah memiliki Tim Keselamatan Kebakaran Gedung (K2G) dan Bencana Alam. Selain itu kita juga selalu mengadakan safety briefing sebelum melakukan rapat atau kegiatan lainnya".

\section{Assembly Point}

Aseembly point di Puskesmas Kecamatan Cipayung ini telah sesuai dengan Undangundang No. 1 tahun 1970 tentang Keselamatan Kerja, pasal 3 ayat 1 poin d yang menyatakan "Memberi kesempatan atau jalan menyelamatkan diri pada waktu kebakaran atau kejadian-kejadian yang berbahaya".

Dari hasil wawancara dengan Tim Penanggung Jawab Keselamatan Kebakaran Gedung (K2G) dan Bencana Alam Puskesmas Kecamatan Cipayung didapatkan informasi "Pada tiap lantai di Puskesmas Kecamatan Cipayung telah dilengkapi dengan petunjuk arah menuju assembly point, sedangkan assembly point berada di halaman parkir bagian depan gedung Puskesmas yang telah dilengkapi dengan papan tanda yang jelas".

\section{Tanda Peringatan}

Hal ini telah sesuai dengan Undangundang No. 1 tahun 1970 tentang Keselamatan Kerja Pasal 14 point b yang menyatakan bahwa "Pengurus diwajibkan memasang dalam tempat kerja yang dipimpinnya, semua gambar keselamatan kerja yang diwajibkan dan semua bahan pembinaan lainnya, pada tempat-tempat yang mudah dilihat dan terbaca menurut petunjuk pegawai pengawas atau ahli keselamatan kerja”.

Dari hasil wawancara dengan Tim Penanggung Jawab Keselamatan Kebakaran Gedung (K2G) dan Bencana Alam Puskesmas Kecamatan Cipayung didapatkan informasi "Puskesmas Kecamatan Cipayung telah memasang Prosedur Keadaan Darurat bila terjadi Kebakaran atau Gempa Bumi pada setiap lantai dan lift di Gedung Puskesmas Kecama- 
tan Cipayung".

\section{Upaya Pencegahan Kebakaran}

Kegiatan pelatihan pemadam kebakaran atau biasa disebut penyegaran yang ada di Puskesmas Kecamatan Cipayung ditujukan kepada karyawan baru dan karyawan lama yang harus mengikuti training atau pelatihan. Training untuk pekerja di Puskesmas Kecamatan Cipayung dilakukan setiap 6 bulan sekali yang di latih oleh Tim Pemadam Kebakaran (DAMKAR) Jakarta Timur. Training atau pelatihan ini dilakukan bertujuan agar apabila terjadi kebakaran semua pekerja tidak panik dan bisa menanggulangi kebakaran denga menggunakan alat pemadam api yang telah ada.

Hal ini telah sesuai dengan Kepmenaker No. Kep-186/MEN/1999 tentang Unit Penanggulangan Kebakaran di Tempat Kerja yaitu pasal 2 ayat 1 yang menyebutkan "Pengurus ataun pengusaha wajib mencegah, mengurangi, dan memadamkan kebakaran, latihan penanggulangan kebakaran di tempat kerja".

Dari hasil wawancara dengan Tim Penanggung Jawab Keselamatan Kebakaran Gedung (K2G) dan Bencana Alam Puskesmas Kecamatan Cipayung didapatkan informasi "Puskesmas Kecamatan Cipayung telah melakukan pelatihan dasar pemadam kebakaran kepada karyawan secara rutin setiap 6 bulan sekali bekerja sama dengan Dinas Pemadam Kebakaran Jakarta Timur. Kegiatan pelatihan terdiri dari pemaparan materi, simulasi evakuasi apabila terjadi kebakaran dan evaluasi kegiatan".

\section{Upaya Penanggulangan Kebakaran Tindakan Penyelamatan}

Untuk pekerja yang berada pada tempat terjadinya kebakaran agar melakukan upaya penyelamatan diri dengan menjauh dari sumber kebakaran keluar melalui pintu darurat yang ada dengan mengikuti arah yang ada dan mendekat atau berkumpul di assembly Point. Setelah itu akan ada Tim Penanggulangan Keadaan Darurat datang untuk mengevakuasi dan membawa semua pekerja ke assembly Point lantai dasar.

Hal ini telah sesuai dengan UndangUndang No.1 Tahun 1970 pada pasal 3 ayat (1) point (d) menyebutkan "syarat-syarat keselamatan kerja untuk memberi kesempatan atau jalan menyelamatkan diri pada waktu kebakaran atau kejadian-kejadian lain yang berbahaya".

Dari hasil wawancara dengan Tim Penanggung Jawab Keselamatan Kebakaran Gedung (K2G) dan Bencana Alam Puskesmas Kecamatan Cipayung didapatkan informasi "Puskesmas Kecamatan Cipayung telah memiliki Standar Operasional Prosedur (SOP) mengenai Penanganan Penanggulangan Kebakaran yang telah di sosialisasikan kepada karyawan".

\section{Tim Pemadam Kebakaran}

Tim pemadam kebakaran di Puskesmas Kecamatan Cipayung bekerja secara shift. Untuk setiap shift baik pagi, siang maupun malam tim pemadam kebakaran yang berjaga 1 kelompok dengan jumlah anggota 7 orang yang terdiri dari 1 orang komando, 2 orang petugas pemadam api, 2 orang petugas evakuasi, 2 orang petugas pengaman / P3K.

Hal ini telah sesuai dengan Kepmenaker No.Kep. 186/MEN/1999 Pasal 2 (b) dan (d) yaitu, "Kewajiban mencegah, mengurangi, dan memadamkan kebakaran di tempat kerja yang meliputi; penyediaan sarana deteksi, alarm sistem, pemadam kebakaran, sarana evakuasi, dan pembentukan unit penanggulangan kebakaran di tempat kerja".

Dari hasil wawancara dengan Tim Penanggung Jawab Keselamatan Kebakaran Gedung (K2G) dan Bencana Alam Puskesmas Kecamatan Cipayung didapatkan informasi "Puskesmas Kecamatan Cipayung telah memiliki Tim pemadam kebakaran yang secara resmi dikukuhkan melalui Surat Keputusan Kepala Puskesmas Kecamatan Cipayung tentang Struktur Tim Penanggung Jawab Keselamatan Kebakaran Gedung (K2G) dan Bencana Alam disertai dengan uraian tugas dari masing-masing petugas".

\section{Analisa SWOT Strength (Kekuatan)}

Kekuatan yang dijadikan modal oleh Puskesmas Kecamatan Cipayung dalam menjalankan upaya pencegahan dan penanggulangan kebakaran di tempat kerja. Antara lain adalah :
a. Puskesmas
Kecamatan
Cipayung
mendapatkan dukungan dana dari pemerintah setempat, dimana diberikann- 
ya anggaran khusus untuk upaya pencegahan dan penanggulangan kebakaran di tempat kerja.

b. Puskesmas Kecamatan Cipayung memiliki desain bangunan yang memenuhi standar keamanan dan keselamatan untuk pasien dan pekerja.

c. Puskesmas Kecamatan Cipayung telah memiliki Alat Pemadam Api Ringan (APAR) yang jumlahnya mencukupi dan berfungsi dengan baik.

d. Puskesmas Kecamatan Cipayung telah memiliki Tim Pemadam Kebakaran di setiap lantainya, dilengkapi dengan tupoksi yang jelas pada masing-masing bagian.

e. Puskesmas Kecamatan Cipayung telah rutin melakukan pelatihan mengenai cara pencegahan dan penanggulangan kebakaran kepada para tenaga kerja.

\section{Weakness (Kelemahan)}

Tidak mutlak dengan segala kekuatannya, Puskesmas Kecamatan Cipayung juga memiliki kelemahan dalam menjalankan upaya pencegahan dan penanggulangan kebakaran di tempat kerja. Berikut adalah analisa SWOT mengenai kelemahan yang dimiliki, sehingga dapat dijadikan motivasi untuk upaya perbaikannya.

a. Puskesmas Kecamatan Cipayung tidak dapat melakukan pengadaan secara mandiri untuk sarana pencegahan dan penanggulangan kebakaran, dikarenakan anggaran yang telah diatur oleh pemerintah pusat pada setiap tahunnya.

b. Adanya beberapa karyawan di Puskesmas Kecamatan Cipayung yang masih memiliki kesadaran rendah terhadap upaya pencegahan dan penanggulangan kebakaran di tempat kerja.

c. Puskesmas Kecamatan Cipayung belum memiliki tenaga Ahli K3 yang kompeten untuk menangani pencegahan dan penanggulangan kebakaran di tempat kerja.

\section{Opportunities (Peluang)}

Berikut adalah kesempatan atau peluang yang dapat dibidik oleh Puskesmas Kecamatan Cipayung dalam hal upaya pencegahan dan penanggulangan kebakaran di tempat kerja.

a. Puskesmas Kecamatan Cipayung memiliki kesempatan untuk menambah formasi tenaga kerja Ahli K3 yang kompeten untuk menangani pencegahan dan penanggulangan kebakaran di tempat kerja.

b. Setiap tahunnya Puskesmas Kecamatan Cipayung selalu diberikan kesempatan untuk mengikuti pelatihan mengenai upaya pencegahan dan penanggulangan kebakaran di tempat kerja.

\section{Threat (Ancaman)}

Berikut adalah beragam ancaman yang mungkin dihadapi oleh Puskesmas Kecamatan Cipayung dalam menjalankan upaya Pencegahan dan Penanggulangan Kebakaran di tempat kerja.

a. Kebijakan Pemerintah. Mungkin seringkali luput dari perhatian bahwasannya ketentuan yang dibuat oleh pemerintah kadang cukup besar pengaruhnya terhadap kelangsungan sebuah Puskesmas yang berada langsung dibawah Pemerintah.

b. Pihak Ketiga yang tidak konsisten dalam memberikan pelayanan. Pihak ketiga yang dimaksud dapat berupa pihak isi ulang APAR, pihak konsultan pelatihan $\mathrm{K} 3$, dll.

c. Letak Puskesmas Kecamatan Cipayung yang berada di dekat pemukiman warga, memiliki potensi bahaya kebakaran.

Dari analisa SWOT diatas dapat disimpulkan bahwa dari berbagai kekuatan dan peluang yang ada pada Puskesmas Kecamatan Cipayung, maka segala bentuk ancaman serta kelemahan yang ada pada Puskesmas Kecamatan Cipayung masih dapat terkendali dengan baik.

\section{Tabel Perbandingan}

Dari hasil perbandingan yang dilakukan terhadap hasil wawancara dan pengamatan lapangan dengan Standar Operasional Prosedur (SOP) yang ada di Puskesmas Kecamatan Cipayung, maka dapat disimpulkan bahwa pelaksanaan pencegahan dan penanggulangan kebakaran di Puskesmas Kecamatan Cipayung telah sesuai dengan Standar Operasional Prosedur (SOP) yang ada (Lihat lampiran, tabel 1).

\section{KESIMPULAN DAN SARAN}

Dari hasil observasi dan wawancara, maka dapat disimpulkan bahwa Puskesmas Kecamatan Cipayung telah melaksanakan 
upaya pencegahan dan penanggulangan kebakaran antara lain dengan penyediaan sarana pemadam kebakaran seperti APAR, tim pemadam dan usaha-usaha lain seperti pemasangan fire alarm system, tanda peringatan dan tersedianya assembly point. Saran yang dapat diberikan adalah untuk penambahan pemasangan dan penempatan poster atau papan peringatan, penambahan sarana pemadam kebakaran seperti water sprinkle dan hydrant, peningkatan wawasan dan ketegasan terhadap peraturanperaturan yang ada dan peningkatan pelatihan mengenai pencegahan dan penanggulangan kebakaran kepada karyawan.

\section{DAFTAR PUSTAKA}

Chairin Noor, A., Andri, M., Yani, A., \& Sudirman, S. (2017). Legal Aspects Occupational Safety and Health of the Work Force in the Bussiness Of Dinamis Abadi City Of Palu. PROMOTIF: Jurnal Kesehatan Masyarakat, 7(2), 131-135. Retrieved from http:// jurnal.unismuhpalu.ac.id/index.php/ PJKM/article/view/86

Ditjen Binkesmas Depkes. 2005. PedomanPuskesmas dalam Penanggulangan Bencana. Jakarta.

Suma'mur, 1989. Keselamatan Kerja dan Pencegahan Kecelakaan. Jakarta : CV Haji Masagung.

Santoso Gempur, 2004. Manajemen Keselamatan dan Kesehatan Kerja. Jakarta : Prestasi Pustaka.

Undang-Undang No 1 Tahun 1970 : Tentang Keselamatan Kerja

Kepmenaker No.Kep. 186/MEN/1999

Kepmenaker No. Kep. 186/MEN/1999 Pasal 2 (b)

Kepmenaker RI No.Kep- 186/MEN/1999 tentang Unit Penanggulangan Kebakaran di Tempat Kerja (BAB II Pasal 5)

Kepmenaker No. Kep-186/MEN/1999 tentang Unit Penanggulangan Kebakaran di Tempat Kerja yaitu pasal 2 ayat 1 
LAMPIRAN

Tabel 1. Perbandingan Hasil Wawancara dan Pengamatan Lapangan dengan Standar Operasional Prosedur

\begin{tabular}{l}
\hline HASIL WAWANCARA DAN PENGAMA- \\
TAN LAPANGAN \\
\hline Hasil Pengamatan Penggunaan APAR \\
Langkah-langkah : \\
Petugas mencabut / menarik ring penga- \\
man \\
Petugas menarik keluar selang APAR \\
Petugas mengarahkan selang APAR ke \\
dasar sumber api \\
Petugas menekan tuas APAR \\
Petugas menyemprotkan APAR mengiku- \\
ti arah angin \\
Petugas menghubungi UPTD dinas \\
pemadam kebakaran bila tidak tera- \\
tasi
\end{tabular}

Hasil Wawancara Mengenai Penanganan Penanggulangan Kebakaran

Langkah-langkah :

Bila terjadi kebakaran, alarm akan berbunyi secara otomatis

Petugas akan melakukan tindakan pemberitahuan kepada seluruh karyawan dan pengunjung bahwa telah terjadi kebakaran dengan pengeras suara dan menenangkan karyawan dan pengunjung agar tidak panik.

Petugas yang terdekat dari titik sumber api harus melakukan pemadaman dengan menggunakan APAR (Alat Pemadam Api Ringan) sesuai SOP yang tersedia

Petugas menghimbau kepada karyawan dan pengunjung untuk tidak menggunakan lift disaat turun dari atas gedung, agar tidak terjadi halhal yang tidak diinginkan

Petugas melakukan koordinasi dengan petugas teknisi agar listrik dipadamkan
STANDAR OPERASIONAL PROSEDUR (SOP)

\section{SOP Penggunaan APAR}

Langkah-langkah :

Petugas mencabut / menarik ring pengaman Petugas menarik keluar selang APAR

Petugas mengarahkan selang APAR ke dasar sumber api

Petugas menekan tuas APAR

Petugas menyemprotkan APAR mengikuti arah angin

Petugas menghubungi UPTD dinas pemadam kebakaran bila tidak teratasi

\section{SOP Penanganan Penanggulangan Keba- \\ karan}

Langkah-langkah :

Alarm tanda kebakaran berbunyi secara otomatis

Petugas melakukan tindakan pemberitahuan kepada seluruh karyawan dan pengunjung akan adanya bahaya bencana/kebakaran dengan pengeras suara dan menenangkan karyawan dan pengunjung untuk tidak panik.

Petugas yang terdekat dari titik sumber api harus melakukan pemadaman dengan menggunakan APAR (Alat Pemadam Api Ringan) sesuai SOP yang tersedia

Untuk menghindari hal hal yang tidak diinginkan disarankan untuk tidak menggunakan lift disaat turun dari atas gedung

Petugas melakukan koordinasi dengan petugas teknisi untuk meminta pemadaman listrik agar kebakaran tidak meluas 
Petugas mengarahkan pengunjung menuju tangga darurat dan membantu evakuasi pasien dengan memberi kursi roda/ branchart, atau menggendong menuju arah turun dengan memakai jalur darurat jalan hijau yang terdapat di belakang gedung

Petugas memastikan bahwa seluruh penghuni gedung sudah berada di area titik kumpul evakuasi yang terdapat di Luar Gedung

Apabila Api semakin membesar petugas mengambil tindakan dengan menghubungi Dinas Pemadam Kebakaran

Petugas keamanan membantu mengatur jalur pelintasan mobil pemadam kebakaran agar mobil pemadam tidak tersendat akibat kerumunan massa

Membuat Laporan atas kejadian tersebut untuk disampikan kepada Kepala Puskesmas. Hal ini dilakukan apabila api sudah padam dan situasi dapat dikendalikan
Petugas mengarahkan pengunjung menuju tangga darurat dan membantu pasien yang tidak dapat berjalan sendiri untuk dievakuasi dengan memberi kursi roda/ branchart, atau menggendong menuju arah turun dengan memakai jalur darurat jalan hijau yang terdapat di belakang gedung

Petugas harus dapat memastikan bahwa seluruh penghuni gedung sudah berada di area parkir tempat titik Aman Kumpul evakuasi yang terdapat di Luar Gedung

Apabila Api semakin membesar petugas mengambil tindakan dengan menghubungi Dinas Pemadam Kebakaran

Petugas keamanan yang sudah berada di luar gedung membantu mengatur jalur pelintasan mobil pemadam kebakaran agar mobil pemadam tidak tersendat akibat kerumunan massa hingga mobil pemadam dapat tiba secepatnya

Membuat Laporan atas kejadian tersebut untuk disampikan kepada Kepala Puskesmas. Hal ini dilakukan apabila api sudah padam dan situasi dapat dikendalikan

Sumber : Data primer dan skunder 